Case Reports

\title{
Segmental Mandibular Resection for Conventional Ameloblastoma
}

\author{
${ }^{1}$ Georges Abi Khalil, ${ }^{2}$ Georges Aoun, ${ }^{3}$ Banine Khalifeh and ${ }^{4}$ Toni Zeinoun \\ ${ }^{1,3,4}$ Department of Oral and Maxillofacial Surgery, Faculty of Dental Medicine, Lebanese University, Beirut, Lebanon \\ ${ }^{2}$ Department of Oral Medicine and Maxillofacial Radiology, Faculty of Dental Medicine, Lebanese University, \\ Beirut, Lebanon
}

\author{
Article history \\ Received: 31-07-2021 \\ Revised: 19-08-2021 \\ Accepted: 26-08-2021 \\ Corresponding Author: \\ Georges Aoun \\ Department of Oral Medicine \\ and Maxillofacial Radiology, \\ Faculty of Dental Medicine, \\ Lebanese University, Beirut, \\ Lebanon \\ Email: dr.georgesaoun@gmail.com
}

\begin{abstract}
Ameloblastoma is an aggressive slow growing benign epithelial odontogenic tumor usually associated with an unerupted third molar. In this report, we present the case of a 71-year-old male with a large swelling on the left mandibular region causing a remarkable facial asymmetry. After clinical, radiological and histopathological examinations the diagnosis of conventional ameloblastoma was made. To avoid probable recurrence our treatment choice was a segmental mandibular resection with the placement of a reconstructive titanium plate to maintain the space for subsequent bone graft.
\end{abstract}

Keywords: Ameloblastoma, Conventional, Segmental Resection, Titanium Plate

\section{Introduction}

Ameloblastoma is a rare benign odontogenic tumor affecting the jaws (Wright and Soluk Tekkesin, 2017). Firstly, described by Cusack in 1827, it was lately named adamantinoma by the French physician Louis-Charles Malassez in 1885 and ameloblastoma by Ivey and Churchill in 1930 (Cusack, 1827; Malassez, 1885; Ivey and Churchill, 1930). It commonly occurs in the mandible, especially in the angle and the ramus and less often in the maxilla with no significant sex predilection (Masthan et al., 2015; McClary et al., 2016).

In 2017, ameloblastomas were classified by W.H.O into three categories: (a) Unicystic, (b) conventional (formerly known as solid/multicystic), (c) extra osseous/peripheral (Masthan et al., 2015; Cadavid et al., 2019). It is important to note that in this new classification, the designation solid/multicystic was rejected to avoid possible confusion with the unicystic lesion and the desmoplastic type included in the old classifications, was reclassified as a histological subdivision (Cadavid et al., 2019; Speight and Takata, 2018).

Unicystic ameloblastoma is a less aggressive subtype of intraosseous ameloblastomas with a low rate of recurrence. It represents $15 \%$ of all ameloblastomas and appears more frequently in the second or third decade.

Histologically, several subtypes of conventional ameloblastomas can be identified based on cell
Clinically and radiologically, it resembles to an odontogenic cyst (Masthan et al., 2015).

Histopathologically, unicystic ameloblastomas present three subdivisions, based on the tumor cell proliferation extent inside the cyst wall: (a) luminal, (b) intraluminal and (c) mural (the lesion invades the wall acting as a conventional ameloblastoma) (Cadavid et al., 2019; Garcia et al., 2016).

Treatment of unicystic ameloblastomas remains controversial. For many surgeons, enucleation and curettage of the neighboring bone can be useful, especially in young patients and in luminal and intraluminal subtypes; for others, the high recurrence rates following conservative treatment protocols makes the radical surgical removal an indication (Garcia et al., 2016; Wright and Vered, 2017).

Conventional type represents $86 \%$ of all ameloblastomas and occurs, usually, in the $3^{\text {rd }}$ and $4^{\text {th }}$ decades of life. It progresses slowly, but invasively infiltrating into contiguous tissue after eroding the cortical bone (Masthan et al., 2015).

Radiographically, conventional ameloblastomas show extensive, radiolucent, multinodular images, with a typical "soap bubble-like" appearance. The cortical plate becomes thin, expanded and sometimes eroded, with the linked non erupted tooth displaced. The roots of the adjacent teeth undergo a clear resorption (Dunfee et al., 2006).

morphological patterns: (a) follicular, (b) plexiform, (c) acanthomatous, (d) granular, (e) desmoplastic and (f) 
basal. The follicular and the plexiform subtypes present the highest incidence among the others (Cadavid et al., 2019; Effiom et al., 2018).

Radical surgery with $1.5-2 \mathrm{~cm}$ beyond the radiological margins and resection of adjacent soft tissue is the treatment of choice for conventional ameloblastoma; a long term follow-up is required (Effiom et al., 2018; Shen et al., 2015).

The extra osseous/peripheral ameloblastoma is found exclusively in the gingival tissue and/or the alveolar mucosa (Masthan et al., 2015); it infiltrates the adjacent tissues without involving the underlying bone.

Clinically, it presents as an Exophytic lesion mimicking the fibrous epulis. Generally, no radiological evidence of bone involvement could be found. It mostly occurs in the premolar region of the mandible (32.6\%), followed by the maxillary tuberosity (Philipsen et al., 2001).

Histologically, the peripheral type shows islands of ameloblastic epithelium, with a pattern comparable to the conventional ameloblastoma (Effiom et al., 2018).

The peripheral ameloblastomas are usually treated with a wide local excision (Chae et al., 2015; Borrello et al., 2016). However, considering the recurrence frequency reported (9 to19\%), a long term follow-up is required (Borrello et al., 2016).

Finally, it is important to highlight the presence of the metastasizing ameloblastomas; these entities present the same histological aspects of the non-metastasizing and consequently the diagnosis can only be made when metastasis took place (Berger et al., 2012). Their etiology may include: (a) large and/or lately diagnosed tumors, (b) multiplicity of recurrences, (c) failure of previous surgical treatments, (d) plexiform histological aspect (Dissanayake et al., 2011). Metastasizing ameloblastomas to the lung are the most frequent, followed by the cervical lymph nodes, the diaphragm, the liver and the brain (Berger et al., 2012; Rotellini et al., 2016).

Radical surgery is indicated for the metastasizing ameloblastomas followed by a mandatory thorough long-term follow-up; role of chemotherapy and/or radiation has yet to be defined (Rotellini et al., 2016).

This report describes an extensive mandibular conventional ameloblastoma of a 71-yearold male removed surgically using the segmental resection technique followed by bone graft reconstruction, thus limiting the occlusal disorders and restoring the form and the function of the mandible.

\section{Case Report}

A 71-year-old male presented to the department of Oral and Maxillofacial Surgery, Faculty of Dental Medicine, Lebanese University, complaining of a large slow growing, painless left mandibular swelling of two years' duration which was progressively increasing in size in the last two months, causing facial asymmetry, limitation of mouth opening, chewing difficulty and ulcerated and bleeding mucosa.

Medical history revealed controlled diabetes and a cardiovascular surgery dating back 13 years.

Extra oral examination exposed a painless, non-tender large swelling with a $3 \times 2 \mathrm{~cm}$ necrotizing skin at the top of the lump. The skin nearby the mass in the preauricular region showed a benign melanocytic nevus (Fig. 1).

On palpation, no regional lymphadenopathy was noticed.

Intraoral examination showed a large irregular lobulated ulcerated lesion (Fig. 2).

A coronal and axial view of CT scan showed a large expansile lesion on the left mandibular region extending from the posterior border of the ramus of mandible till the canine region reaching the zygomatic arch (Fig. 3).

\section{Thoracic-Abdominal-Pelvic CT Scan Showed no Metastasis}

Clinical and radiological differential diagnosis includes ossifying fibroma, odontogenic myxoma, central giant cell granuloma, ameloblastic fibroma, ameloblastic fibro sarcoma and calcifying epithelial odontogenic tumor.

Incisional biopsy of the oral cavity mass from different regions of the tumor was done under local anesthesia with minimal bleeding; the result of the histopathological examination showed an ameloblastoma with Malpighian metaplasia with a neoplastic proliferation formed by polygonal cells with irregular nuclei.

Our treatment plan consisted of segmental mandibular resection with safe margin and direct reconstruction of mandible using a titanium reconstructive plate to stabilize the mandible and bone graft after the intraoral soft tissue healing.

The patient was scheduled for the surgery after obtaining the medical clearance from his physician and receiving prophylactic antibiotic therapy.

Under general anesthesia, through a nasotracheal intubation, two arch bars were placed for intermaxillary fixation to maintain the original occlusion, followed by an incision extending from the mastoid region to the midline of the submental region. Two semilunar incisions around the necrotizing skin were performed (Fig. 4).

A flap was raised, ligation of the facial vein and artery was carried out and dissection of the marginal branch of the facial nerve was performed to avoid its injury (Fig. 5).

After dissecting the lesion and excising the necrotizing skin, we discovered a smooth and thin wall of the tumor. At the inferior border of the mandible, drilling was performed to prepare two landmarks anteriorly and posteriorly to the tumor and two drills were placed parallel to each other, where the distance was measured with a value of $5.5 \mathrm{~cm}$ to respect the original position of the mandibular ramus and condyle in the glenoid fossa (Fig. 6).

Intraoral incision was performed in the lingual and buccal mucosa away from the tumor within $1 \mathrm{~cm}$ safety margins. A segmental resection of the mandible with 1.5 
$\mathrm{cm}$ of safety margin was carried out using electrical surgical saw, followed by the dissection and excision of the tumor. After total excision of the tumor and achieving hemostasis, the drills were placed in the prepared holes in a distance of $5.5 \mathrm{~cm}$ using a ruler and both mesial and distal fragments were fixed using reconstructive titanium plate with a six titanium screws to ensure the mandibular outline and stability after surgery (Fig. 7).

A closure of the mucosal and cutaneous wound was done followed by the placement of a dressing respecting the hydrostatic pressure.

After the surgery, the patient had no alteration of facial movements and was followed up for 1 month (Fig. 8).

The histopathological analysis of the tumor revealed a plexiform ameloblastoma with a Malpighian metaplasia t $=9 \mathrm{~cm}$. Invasion of bone, soft tissue and skin with the formation of an inflammatory fistula was observed. The limits of the excision were free from cells tumor. Three months after the surgery, a fistula in the suture line of the excised necrotizing skin, exposing the reconstructive plate was observed, leading to a communication with the oral cavity. A transposition flap on the cutaneous side and an advancement flap on the mucosal side were performed to repair the fistula (Fig. 9).

The patient was followed up for 3 years and showed no other complications.

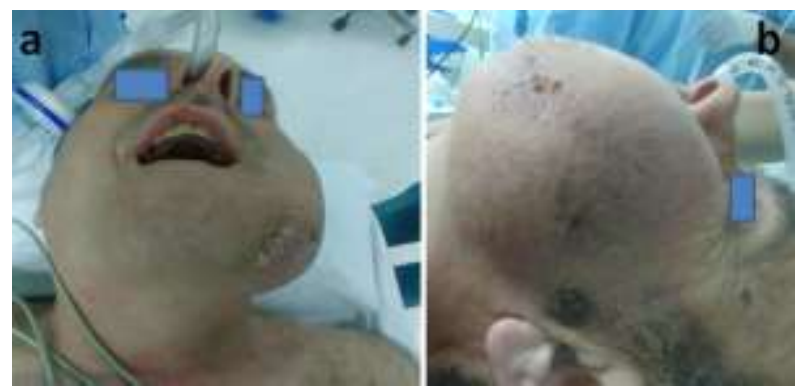

Fig. 1: Extraoral examination showing (a) a large lesion with asymmetry of the face and necrotizing skin at the top of the lump; (b) a melanocytic nevus in the preauricular region

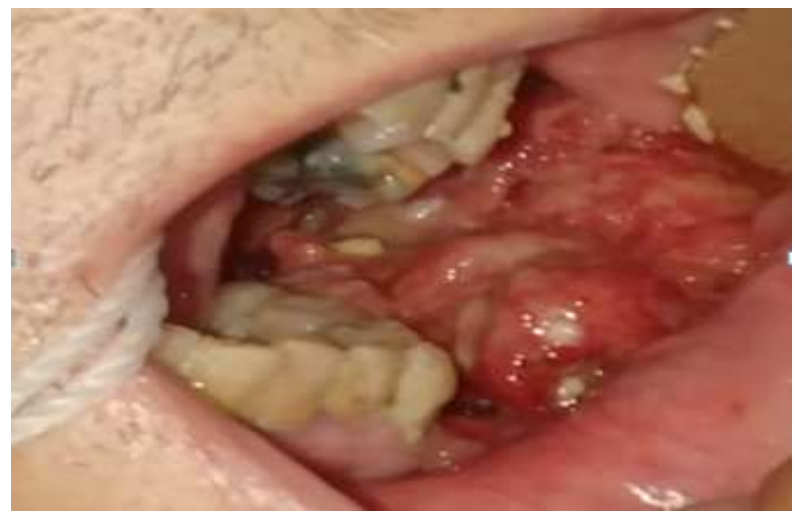

Fig. 2: Intraoral examination showing a large irregular ulcerated lesion that had a tumoral aspect
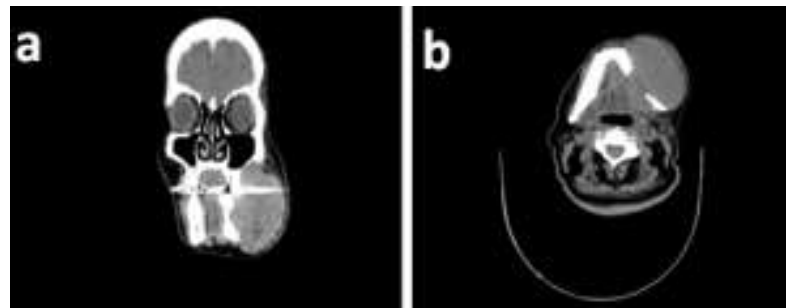

Fig. 3: (a) Coronal and (b) axial CT scans showing a large expansile lesion on the left mandibular region
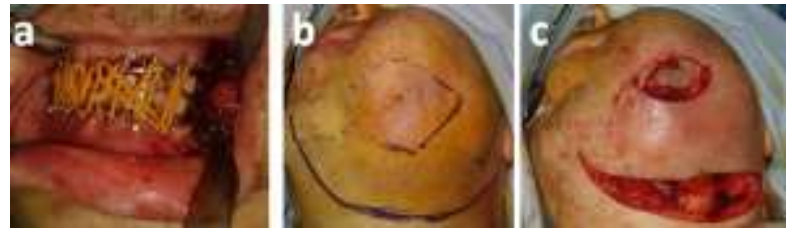

Fig. 4: (a) Arch bars placement for intermaxillary fixation; (b) demarcation line starting from the mastoid region till the midline of the submental region and around the necrotizing skin at the top of the lump; (c) incision on the demarcation line

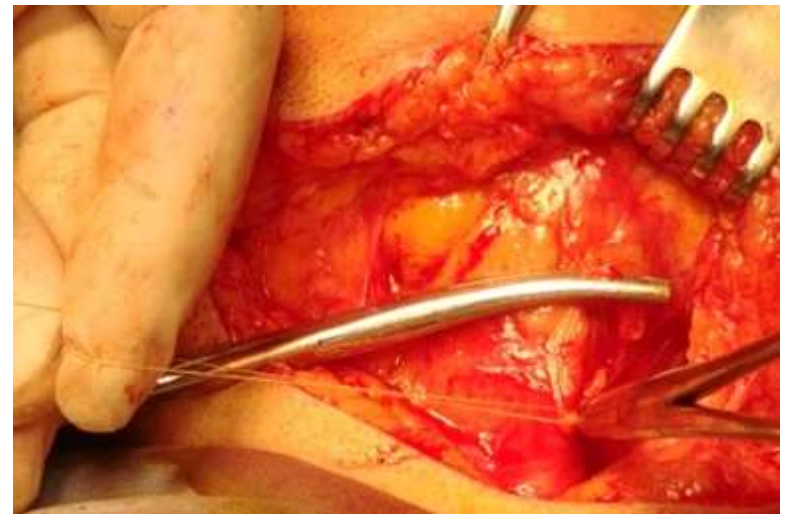

Fig. 5: Dissection and ligation of the facial vein and artery
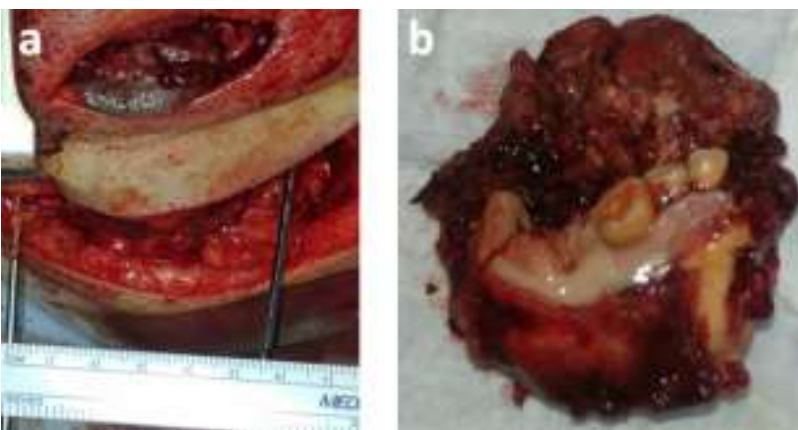

Fig. 6: (a) Two landmarks were prepared anteriorly and posteriorly to the tumor and the distance was measured between two parallel drills with a value of $5.5 \mathrm{~cm}$ to ensure the original position of the mandibular ramus and condyle in the glenoid fossa; (b) the excised tumor 

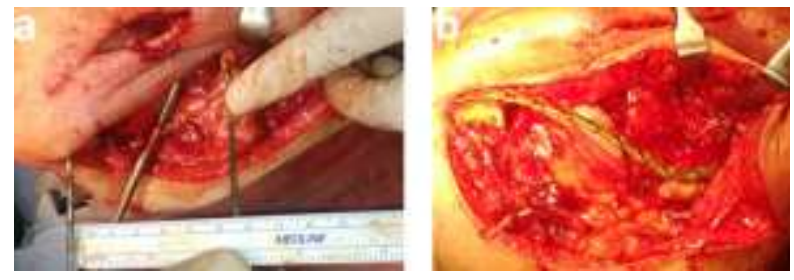

Fig. 7: (a) After excision of the tumor, two parallel drills were placed in the prepared landmarks in a distance of $5.5 \mathrm{~cm}$ for the fragments fixation in their original position using a reconstructive titanium plate; (b) placement of the reconstructive titanium plate to maintain the optimal mandibular space
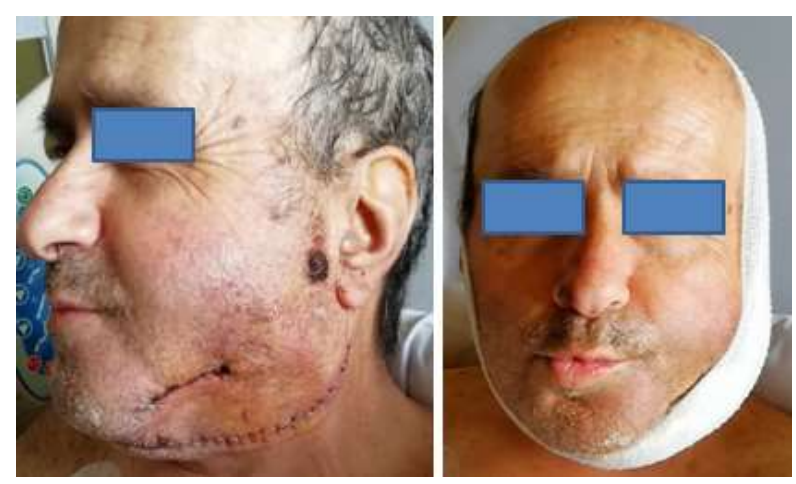

Fig. 8: Follow up and normal facial expressions indicating preservation of the facial nerve
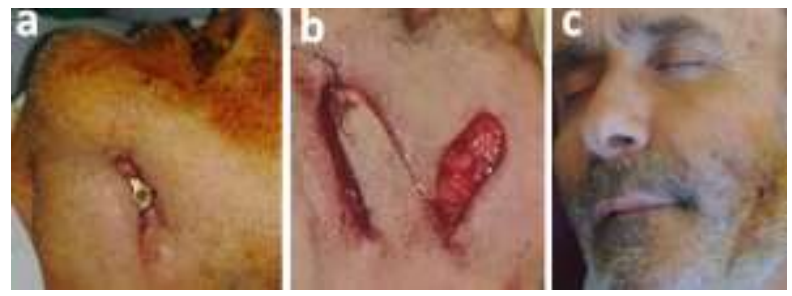

Fig. 9: (a) Fistula formation in the suture line of the excised necrotizing skin exposing the reconstructive plate; (b) a skin transposition and mucosal advancement flap were performed to repair the fistula; (c) Follow up after 10 days

\section{Discussion}

Ameloblastoma, principally the conventional type, is a locally aggressive odontogenic tumor. Untreated, it infiltrates through the cortical bone and extends to the adjacent tissues. The majority of cases are reported in a mean age of 35 years, without sex predilection. $80 \%$ of ameloblastomas arise in the mandible, generally in the posterior regions. Maxillary ameloblastomas, especially located posteriorly, could extend intracranial after maxillary sinus invasion. Patients may consult for signs and symptoms such as: (a) a Slow-growing swelling, (b) facial asymmetry, (c) loose teeth, (d) pain, (e) paresthesia, etc. or the lesion can, in some cases, be detected fortuitously on radiographs taken for routine dental examination (Masthan et al., 2015; Mendenhall et al., 2007).

The treatment of choice of conventional ameloblastomas is surgery with a large resection, due to elevated recurrence rate (13-15\%) (Masthan et al., 2015). Many surgeons suggest a $1.5-2 \mathrm{~cm}$ margin beyond the radiological limit to guarantee the removal of all tumor debris. Moreover, a follow-up of 5 to 10 years after surgery is essential (Masthan et al., 2015).

In the present case, we have presented an invasive extended conventional ameloblastoma localized in left mandibular region of a 71-year-old male. After histological and radiological confirmations, a radical segmental mandibular resection was performed.

It is to be noted that the following steps are mandatory to insure a successful surgical treatment: (a) the intermaxillary fixation aiming to retrieve the original occlusion, (b) the preparation of the two landmarks intended to conserve the original position of the mandibular condyle in the glenoid fossa and the ramus, (c) the placement of the reconstructive titanium plate designed to maintain the mandibular function and space and (d) the autogenous iliac crest bone graft to replace the missing bone.

After 3 years from the surgery, our patient is still under observation with no evidence of recurrence.

\section{Conclusion}

The segmental resection for multisystem ameloblastoma followed by the insertion of the reconstructive titanium plate is a predictable procedure for oral rehabilitation and should be considered when treating an extensive mandibular ameloblastoma.

\section{Informed Consent Statement}

Written informed consent was obtained from the patient in this study.

\section{Author's Contribution}

Georges Abi Khalil: Performed the surgery.

Georges Aoun: Designed and directed the article and wrote the paper. Performed the assessment.

Banine Khalifeh: Performed the assessment.

Toni Zeinoun: Performed the assessment

\section{Ethics}

This article is original and contains unpublished material. The corresponding author confirms that all of the other authors have read and approved the manuscript and no ethical issues involved 


\section{References}

Berger, A. J., Son, J., \& Desai, N. K. (2012). Malignant ameloblastoma: Concurrent presentation of primary and distant disease and review of the literature. Journal of oral and maxillofacial surgery, 70(10), 2316-2326. doi.org/10.1016/j.joms.2011.11.004

Borrello, R., Bettio, E., Bacci, C., Valente, M., Sivolella, S., Mazzoleni, S., \& Berengo, M. (2016). A conservative approach to a peripheral ameloblastoma. Case reports in dentistry, 2016. doi.org/10.1155/2016/8254571.

Cadavid, A. M. H., Araujo, J. P., Coutinho-Camillo, C. M., Bologna, S., Junior, C. A. L., \& Lourenço, S. V. (2019). Ameloblastomas: Current aspects of the new WHO classification in an analysis of 136 cases. Surgical and Experimental Pathology, 2(1), 1-6. doi.org/10.1186/s42047-019-0041-z

Chae, M. P., Smoll, N. R., Hunter-Smith, D. J., \& Rozen, W. M. (2015). Establishing the natural history and growth rate of ameloblastoma with implications for management: Systematic review and meta-analysis. PloS one, 10(2), e0117241.

doi.org/10.1371/journal.pone.0117241

Cusack, J. W. (1827). Report of the amputations of the lower jaw. Dublin Hosp Rec, 4, 1-38.

Dissanayake, R. K. G., Jayasooriya, P. R., Siriwardena, D. J. L., \& Tilakaratne, W. M. (2011). Review of metastasizing (malignant) ameloblastoma (METAM): Pattern of metastasis and treatment. Oral Surgery, Oral Medicine, Oral Pathology, Oral Radiology and Endodontology, 111(6), 734-741. doi.org/10.1016/j.tripleo.2010.12.018.

Dunfee, B. L., Sakai, O., Pistey, R., \& Gohel, A. (2006). Radiologic and pathologic characteristics of benign and malignant lesions of the mandible. doi.org/10.1148/rg.266055189

Effiom, O. A., Ogundana, O. M., Akinshipo, A. O., \& Akintoye, S. O. (2018). Ameloblastoma: Current etiopathological concepts and management. Oral diseases, 24(3), 307-316. doi.org/10.111/odi.12646.

Garcia, N. G., Oliveira, D. T., \& Rodrigues, M. T. V. (2016). Unicystic ameloblastoma with mural proliferation managed by conservative treatment. Case reports in pathology, 2016. doi.org/10.1155/2016/3089540

Ivey, R. H., \& Churchill, H. R. (1930). The need of a standardized surgical and pathological classification of tumors and anomalies of dental origin. Am Assoc Dent Sch Trans, 7, 240-245.

Malassez, L. C. (1885). Sur les role des débris épithéliaux paradentaires. Masson.
McClary, A. C., West, R. B., McClary, A. C., Pollack, J. R., Fischbein, N. J., Holsinger, C. F., ... \& Sirjani, D. (2016). Ameloblastoma: A clinical review and trends in management. European Archives of Oto-RhinoLaryngology, 273(7), 1649-1661. https://link.springer.com/article/10.1007/s00405015-3631-8

Mendenhall, W. M., Werning, J. W., Fernandes, R., Malyapa, R. S., \& Mendenhall, N. P. (2007). Ameloblastoma. American journal of clinical oncology, 30(6), 645-648.

Masthan, K. M., Anitha, N., Krupaa, J., \& Manikkam, S. (2015). Ameloblastoma. Journal of pharmacy \& bioallied sciences, 7(Suppl 1), S167-S170. doi.org/10.4103/0975-7406.155891

Philipsen, H. P., Reichart, P. A., Nikai, H., Takata, T., \& Kudo, Y. (2001). Peripheral ameloblastoma: Biological profile based on 160 cases from the literature. Oral oncology, 37(1), 17-27. doi.org/10.1016/S1368-8375(00)00064-6

Rotellini, M., Maggiore, G., Trovati, M., Saraceno, M. S., \& Franchi, A. (2016). Metastasizing maxillary ameloblastoma: Report of a case with molecular characterization. Journal of oral \& maxillofacial research, 7(1). doi.org/10.5037/jomr.2016.7105.

Shen, Y. F., Rodriguez, E. D., Wei, F. C., Tsai, C. Y., \& Chang, Y. M. (2015). Aesthetic and functional mandibular reconstruction with immediate dental implants in a free fibular flap and a low-profile reconstruction plate: Five-year follow-up. Annals of plastic surgery, 74(4), 442-446. doi.org/10.1097/SAP.0b013e3182a0dedf.

Speight, P. M., \& Takata, T. (2018). New tumour entities in the 4th edition of the World Health Organization Classification of Head and Neck tumours: Odontogenic and maxillofacial bone tumours. Virchows Archiv, 472(3), 331-339. https://link.springer.com/article/10.1007/s00428017-2182-3

Wright, J. M., \& Tekkesin, M. S. (2017). Odontogenic tumors: where are we in 2017? Journal of Istanbul University Faculty of Dentistry, 51(3 Suppl 1), S10. doi.org/10.17096/jiufd.52886

Wright, J. M., \& Vered, M. (2017). Update from the 4th edition of the World Health Organization classification of head and neck tumours: odontogenic and maxillofacial bone tumors. Head and neck pathology, 11(1), 68-77. https://link.springer.com/article/10.1007\%2Fs12105 $-017-0794-1$ 